Journal of Urban and Regional Analysis, vol. XII, 1, 2020, p. $91-111$

https://doi.org/10.37043/JURA.2020.12.1.6

\title{
LAND COVER IMPACTS TOWARDS THERMAL VARIATION IN THE KUALA LUMPUR CITY
}

\author{
Nurul Amirah ISA ${ }^{1}$, Wan Mohd Naim WAN MOHD ${ }^{1}$, Siti Aekbal SALLEH ${ }^{1}$, \\ Maggie Chel GEE OOI ${ }^{2}$, Andy $\mathrm{CHAN}^{3}$ \\ ${ }^{1}$ Universiti Teknologi MARA, Shah Alam, Malaysia; ${ }^{2}$ National Central University, \\ Taoyuan, Taiwan; ${ }^{3}$ University of Nottingham, Semenyih, Malaysia
}

\begin{abstract}
Physical geography and urban characteristics influence the urban climate conditions. Built-up areas, green urban parks, forest reserves, streets and terrain constitute the climatic interactions within urban areas. These have led to the variation of the urban climate condition throughout the world. Thus, in studying urban climate, the impacts of these factors are crucial to be examined. This study aims to examine the effects of six important factors, namely built-up areas, green covers, terrain elevation, building volume, surface roughness and land use type, which contribute to the variation of the urban climate condition within the Kuala Lumpur City. In this study, the effects of the six factors (urban parameters) towards the air surface temperature variation were statistically tested. Using the Weather Research and Forecasting (WRF) model and the remote sensing technique, the data needed for the analyses were extracted. The Geographical Information System (GIS) was employed as the analysis platform during the study. Based on the Spearman's rho and Mann-Whitney $U$ tests, it was identified that the six urban parameters and the air surface temperature variation are correlated. The further investigation conducted using the Kruskall-Wallis test has identified that only five of the urban parameters showed significant effects toward the air surface temperature variation, which are built-up areas, green covers, terrain elevation, building volume and surface roughness while the land use type was excluded. The findings of this study are very crucial as a pioneer research to integrate the urban climatic information in the urban planning decision making in tropical cities like Kuala Lumpur.
\end{abstract}

Key Words: urban climate, urban parameters, air surface temperature, tropical climate, Kuala Lumpur.

\section{Introduction}

Tropical climate is described as hot and humid with little variations throughout the year. Southern Asia, Southeast Asia, Central America, Central Africa and the Caribbeans are the regions which experience the tropical climate condition due to their geographical locations. These regions are situated on the Equator, which is nearer to the sun, and they obtain direct sun exposure throughout the year (Amos 2017). Thus, more heat is accumulated within these regions as compared to other parts of the world. Other than that, these regions are significantly affected by the Madden-Julian Oscillation (MJO) and the EI Niño-Southern Oscillation (ENSO) which are associated with the northeast and southwest wind blows (Ward et al. 2014). These phenomena fluctuate the annual weather of these tropical regions with intense heat, heavy rainfalls and tropical cyclones (Hwang et al. 2017).

Malaysia is situated in one of those tropical regions. As located near to the Equator, Malaysia experiences typical tropical climate behaviour which is also largely influenced by the AsianAustralian monsoon system (Tangang et al. 2012). In this region, the wind patterns create two tropical monsoons, namely the northeast and the southwest monsoons. The monsoons are caused by the changes in the atmospheric circulation and precipitations which occurred due to the unbalanced heating of land and sea. Both of monsoons bring heavy rainfall which increases the cumulative precipitation and humidity to the country (Wong et al. 2016). The northeast 
monsoon starts from October to March which brings heavy rainfall to the eastern part of Malaysia whereas southwest monsoon strikes in April to September and it brings more precipitation to the west coast regions. April and October are the transitional periods of both monsoons which also contribute to the fluctuate patterns of the annual climate of Malaysia (Tangang et al. 2012).

Previous studies have recorded that the rapid urbanization is responsible with the emergence of UHI (Elsayed 2012, Arifwidodo and Tanaka 2015, Alobaydi et al. 2016). As a developing country, Malaysia has been developed particularly in the west coast of Malay Peninsula. The emergence of important business areas, such as Sungai Besi, Damansara, Cheras, Wangsa Maju and others in this region, resulted in the huge conurbation of the Kuala Lumpur, the capital city of Malaysia. Previous climate-related studies on the Kuala Lumpur city reported that the urbanization process within and around the city leads to the formation of the urban heat island (UHI) phenomenon (Ibrahim and Samah 2011, Buyadi et al. 2013, Salleh et al. 2013).

Previous studies also documented the emergence of the $\mathrm{UHI}$ and its increasing rate of intensity within Kuala Lumpur was described as very distressing (Elsayed 2012, Tangang et al. 2012, Ooi et al. 2017). Elsayed (2012) has found that the UHI intensity in the Kuala Lumpur city is ranging from $4^{\circ} \mathrm{C}$ to $6^{\circ} \mathrm{C}$ under a clear view sky, since the first study conducted by Sani in 1972 . A later study in the city recorded that the magnitude of the UHI intensity has increased up to $8.4^{\circ} \mathrm{C}$ from 1997 to 2013 (Yusuf et al. 2014). Looking at how this situation has worsened, a recent study by Ramakreshnan et al. (2018) urges more studies regarding the UHI intensity with more comprehensive spatial analysis to be conducted in order to analyse the current state of the $\mathrm{UHI}$ issue in Malaysia, especially the Kuala Lumpur city. Additionally, mitigation measures on UHI issues should be well scrutinized as Malaysia is expected to have a blooming population and urbanization rate in the future (Yuen and Kong 2009).

UHI degrades the quality of the urban climate within the city. The alteration of the original climate behaviour is affecting the thermal comfort of city's dwellers in Kuala Lumpur (Shaharuddin et al. 2014). Most climate-related studies suggest that the urban climate behaviour should be well considered during development planning in order to reduce the alteration of the thermal environment within the city for comfortable living (Ibrahim et al. 2014, Acero et al. 2015). Therefore, introducing the urban climate information into the urban planning decision making is a must. In Malaysia, the urban climate aspect is not often considered during the urban planning decision making process. At the beginning of its resurrection from the economic downturn, urban developments are the top priorities leaving the environmental problem less important (Elsayed 2012). Early urban developments in the country gave very little consideration to the environmental aspect, especially the urban climate (Ibrahim et al. 2014). Subsequently, the current practice leads to many consequences of environmental problems.

Even though the urban climatic information is seldom considered in urban planning, this does not mean that the UHI issues are not critical, but rather difficult to assess and implement in real practice due to the lack of tools and expertise on climate-related knowledge among the urban planners (Giridharan 2016). The difficulty of presenting the sophisticated climatology and meteorology information in a way that suits the urban planners and policy makers complicate the integration of climatic information into the urban planning decision making (Grimmond et al. 2010). Recent discoveries have nurtured the importance of climatic knowledge for urban development strategies. Along with the nature of the climate, the urban planners should consider the response of the urban climate towards the urban physical characteristics.

Elsayed (2012) highlighted six main aspects that can alter the urban climate condition, namely the urban fabric and materials, the urban structure, the artificial heat production, evapotranspiration, pollution, and human activities. Among these six aspects, urban structures, 
which encompass the urban physical and geometry, such as building density/volumes, topography and land uses, are often documented as a significant contributor to the urban climate variation especially the thermal environment (Jamei et al. 2015, Kattel and Yao 2018, Isa et al. 2018a). Hence, this study is conducted with the aim to analyse the effects of six urban parameters (which represent the urban physical characteristics) on the air surface temperature of the Kuala Lumpur city.

\section{Methodology}

\section{Study Area}

The investigation was carried out in the Kuala Lumpur City. Located on the west-coast of the Peninsular of Malaysia, the city is surrounded by the state of Selangor (Fig. 1). The city is the heart of Greater Kuala Lumpur, where many economic activities and international conferences are held, making the city to be highly populated with citizens migrating to live in the city. The area covers about $243 \mathrm{~km}^{2}$, with an extent of approximately $24 \mathrm{~km}$ from the north to the south, and with $17 \mathrm{~km}$ from west to east.

The Kuala Lumpur City owns a typical tropical climate, which is hot and humid throughout the year. Since the city is situated in Southeast Asia, the country faces two types of monsoon - the Northeast monsoon and the Southwest monsoon. The climate of the city is also influenced by the El Niño-Southern Oscillation (ENSO), the Indian Ocean Dipole (IOD) and the MaddenJulian Oscillation, which leads to different climate experiences at regional scales.

This city was selected as the case study due to its heterogenous spatial variability. The different urban physical characteristics across the city allow deep examinations on the effects of the urban physical characteristics towards the urban climate condition. The city is made up of unplanned and well-planned urban areas and it has been developed with a various urban geometry.

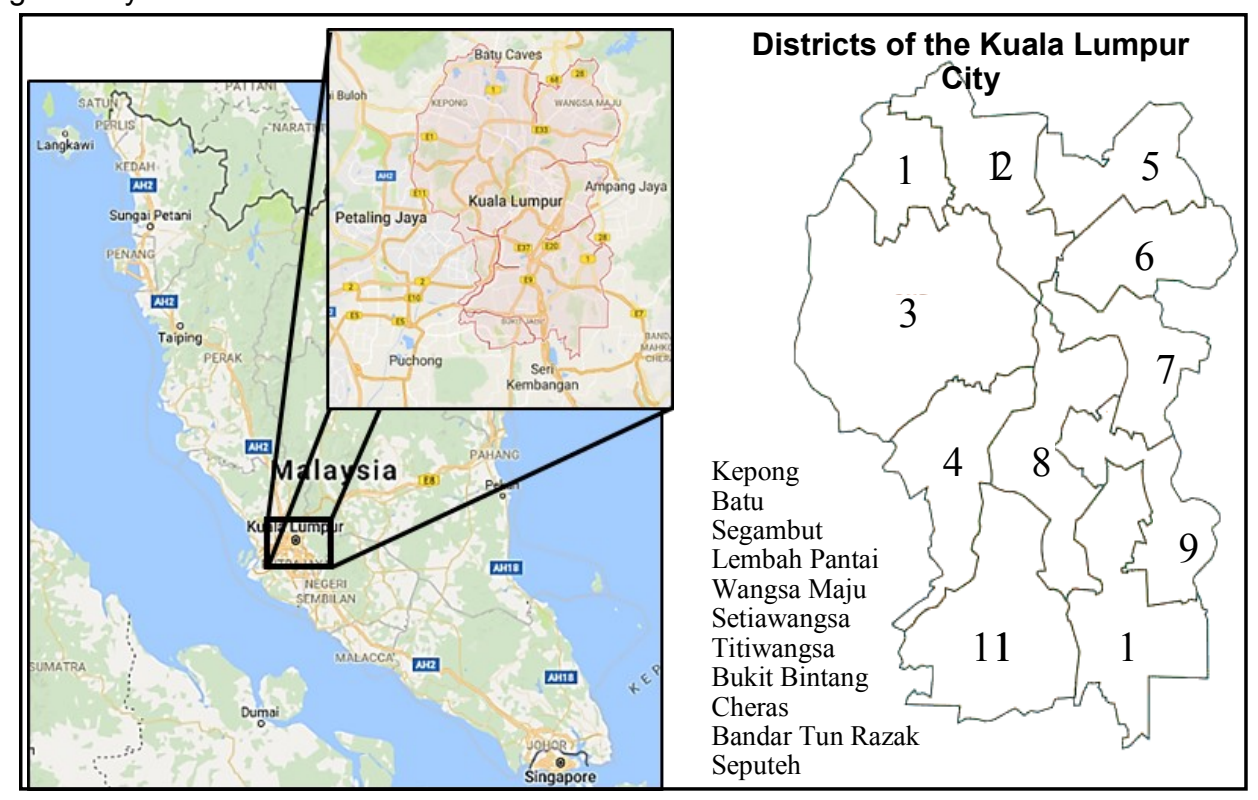

Fig. 1 - Study area 
Kuala Lumpur is surrounded by four main towns which are: Batu Caves in the north, Seri Kembangan in the south, Ampang Jaya in the east, and Petaling Jaya in the west. The city is divided into eleven districts, which serve as administrative subdivisions under the Kuala Lumpur City Council authority.

\section{Data and Materials}

Five different types of datasets were used: Landsat OLI satellite images, LiDAR-based DEM, GIS-based datasets, WRF-ARW lateral boundary data and MMD ground observation data. Table 1 shows the list of used datasets and their related information.

Datasets utilized during the research process

Table 1

\begin{tabular}{|c|c|c|c|c|}
\hline No & Type & Data & Date/Year & Source \\
\hline 1 & Satellite image & $\begin{array}{l}\text { Landsat } 8 \mathrm{OLI} \\
\text { image }\end{array}$ & $24^{\text {th }}$ March 2014 & USGS \\
\hline \multirow{2}{*}{2} & \multirow{2}{*}{ LiDAR-based DEM } & $\begin{array}{l}\text { Digital Terrain } \\
\text { Model }\end{array}$ & 2014 & $\overline{\mathrm{DBKL}}$ \\
\hline & & $\begin{array}{l}\text { Digital Surface } \\
\text { Model }\end{array}$ & 2014 & $\overline{D B K L}$ \\
\hline \multirow{2}{*}{3} & \multirow{2}{*}{ GIS data layer } & Building footprint & 2014 & DBKL \\
\hline & & Land use type & 2014 & JPBD \\
\hline 4 & WRF-ARW input & $\begin{array}{l}\text { Lateral boundary } \\
\text { condition }\end{array}$ & $24^{\text {th }}$ March 2014 & NCAR/NCEP \\
\hline 5 & Ground Observation & $\begin{array}{l}\text { Air surface } \\
\text { temperature and } \\
\text { wind speed }\end{array}$ & $24^{\text {th }}$ March 2014 & MMD \\
\hline
\end{tabular}

The Landsat 8 OLI satellite image of 24th March 2014 was used in this study. The image was chosen due to its minimum cloud cover over the study area. The image of 24th March 2014 is chosen to coincide to the date of the LiDAR and GIS-based dataset and to form the basis to develop the urban climatic model.

The Landsat $8 \mathrm{OLI}$ image was chosen due to the availability of bands used to extract two urban parameter layers, namely the built-up areas and the green cover. In this study, 8 bands (i.e. Band 3, 4, 5, 6, 7, 10 and 11) were used to extract these two urban parameters. These bands include the thermal bands and the bands which are ranging from red to the middle infrared spectrum. The image was also chosen due to its spatial resolution which is suitable for urban parameters mapping. Fig. 2 shows the satellite image utilized in the study. Table 2 shows the specifications of the used image.

Landsat 8 OLI specifications

Table 2

\begin{tabular}{|c|c|}
\hline Name & Landsat 8 OLI \\
\hline Data Format & TIFF \\
\hline Spectral Resolution & 11 bands \\
\hline Spatial Resolution & Visible - NIR - SWIR $=30 \mathrm{~m}$ \\
\cline { 2 - 2 } & Panchromatic $=15 \mathrm{~m}$ \\
\cline { 2 - 2 } & Thermal IR $=100 \mathrm{~m}$ \\
\hline Temporal Resolution & 16 days revisit \\
\hline Swath & $185 \mathrm{~km}$ wide \\
\hline
\end{tabular}




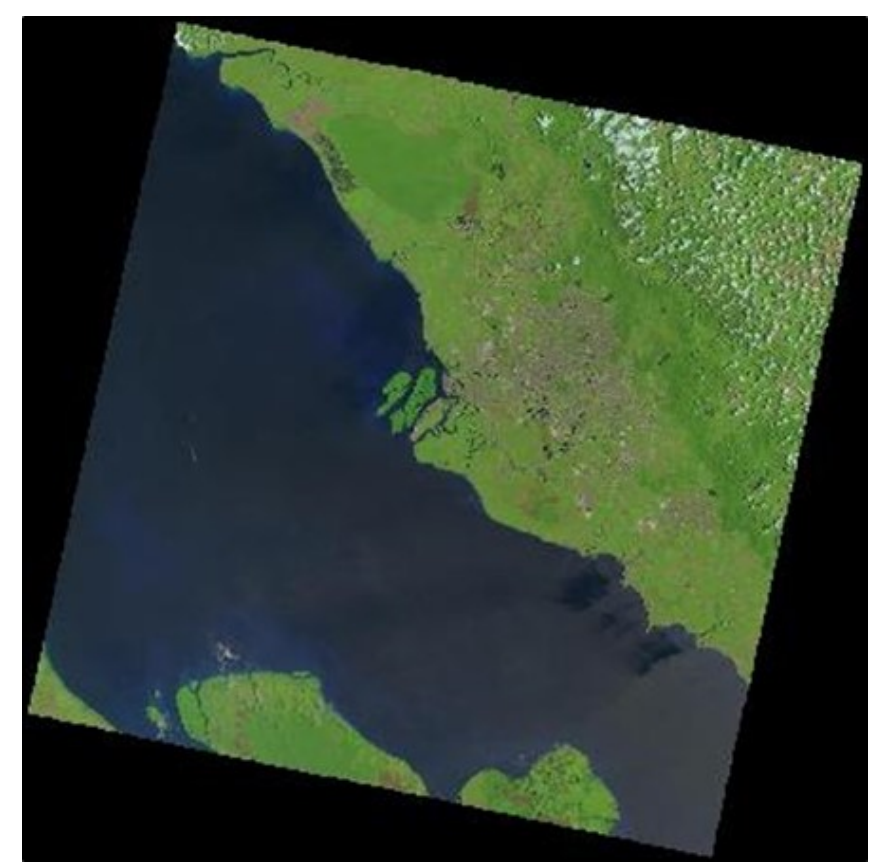

Fig. 2 - The Landsat 8 OLI satellite image of $24^{\text {th }}$ March 2014

The LiDAR-based DEM of 2014 provided by the Kuala Lumpur City Council (DBKL), with a pixel resolution of $0.5 \mathrm{~m}$, was also utilized. The dataset covers the entire area of Kuala Lumpur City. The dataset was chosen due to its high resolution, as well as it covers the entire study area. Using the LiDAR-based DEM, two urban parameters which are the terrain elevation and the surface roughness were derived.

The building footprint and the land use type data layer of 2014 are the two GIS-based vector datasets used in this study. The building footprint data layer was obtained from the Kuala Lumpur City Council (DBKL), while the land use layer was obtained from the Department of Town and Regional Planning of Malaysia (JPBD). The building footprint data layer was used to derive the building volume layer whereas the land use type data layer was used to classify the city into its land uses.

Both data layers are stored in a shapefile format. The building footprint layer consists of 231689 polygons presenting the footprints of each building within the Kuala Lumpur City. This layer is also attributed with the building height information which is used to estimate the building volume. The land use data layer consists of 185296 polygons, demarcating the city into their land uses and purposes. These polygons are classified into 18 different classes of land use types.

The Lateral boundary condition (LBC), or the global climate observation data, represents the boundary condition of the Earth surfaces. These data are required for the dynamic downscaling from mesoscale into regional scales. In nested domains, the LBC is provided by the parent domains for its nest/s. Although several previous studies have disputed the errors 
resulted from the LBCs, studies by Denis et al. (2002) and Amengual et al. (2007) have recommended several measures to minimize these errors. The more recent study of Davies (2014) has shown that the errors resulted from the LBCs can be controlled and they only contribute to small errors.

The present study utilized the NCEP GDAS/FNL 0.25 Degree Global Tropospheric Analyses and Forecast Grids lateral boundary condition datasets to simulate the climate variables using the WRF-ARW simulation. This dataset provides 36 climate variables including the variables needed for this study, namely the air surface temperature. This LBC is chosen since it is prepared for the troposphere layer and it represents a very similar situation to the study carried out by the author. This dataset was also chosen due to its higher spatial and temporal resolution as compared to other LBCs such as the ERA-Interim Project and JRA-25 datasets. The original lateral boundary condition dataset with a spatial resolution of $0.25^{\circ}$ prepared for every three hours was used in this study.

Ground observation datasets (i.e. air surface temperature) were obtained from the Malaysian Meteorological Department (MMD). These datasets were used to validate the simulated air surface temperature. The diurnal pattern of the climate variables was compared against the ground observations. The data was supplied in text format and they contained hourly ground observations of air surface temperature at three different stations. Table 3 shows the MMD stations used for the observation date. The location of the stations on the ground is shown in Fig. 3.

\section{Ground stations involved during both dates}

\begin{tabular}{|c|l|}
\hline Date & \multicolumn{1}{|c|}{ 24 March 2014 } \\
\hline Station 1 & Pusat Pertanian Serdang \\
\hline Station 2 & University of Malaya \\
\hline Station 3 & Subang \\
\hline
\end{tabular}

Fig. 3 - Locations of MMD ground stations

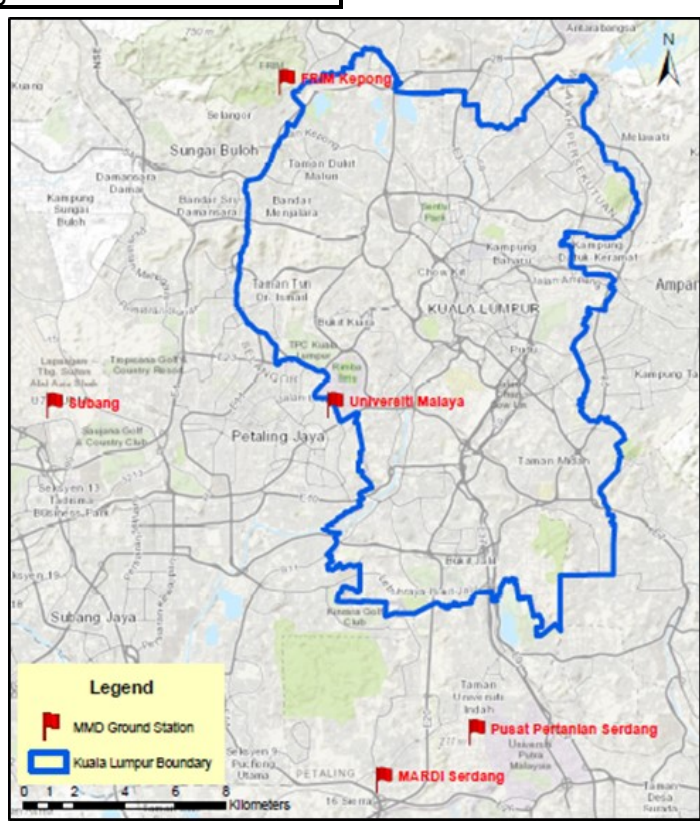


For the purpose of this study, six urban parameters were selected that covered the urban physical characteristics of Kuala Lumpur city, namely the green cover, the built-up areas, the terrain heights, the surface roughness, the building volume and land uses. These urban parameters were tested against the air surface temperature distribution in order to examine the effects of urban heating and urban cooling within the study areas. The evolution of technology through remote sensing, GIS and numerical modelling allows the present study to enhance the data acquisition that is able to cover a larger study area (Ramakreshnan et al. 2018). Therefore, the samples of used data were also improved using this type of technology. Green cover and built-up area were extracted from the remotely-sensed satellite image; terrain heights and surface roughness were derived from the Light Detection and Ranging (LiDAR) dataset; the building volume was estimated from the GIS data layer; the land uses were digitized using a GIS platform; and the air surface temperature was simulated using the Weather Research and Forecasting (WRF) simulation model.

The further analysis employed statistical approaches to identify the relationships between the urban parameters and the air surface temperature distribution of Kuala Lumpur city. In the present study, non-parametric statistical approaches were used due to the nature of the data samples produced that were not normally distributed. Though, the conducted tests were adequate to enlighten the effects of each urban parameter on the urban climate variation. The employed non-parametric statistical tests were the Spearman Rho's test, the Kruskal-Wallis H test and the Mann-Whitney $U$ test. The Spearman's Rho's test was used to investigate the correlation between the urban parameters and the air surface temperature distribution. The Kruskall-Wallis $\mathrm{H}$ test was used to further the investigation in order to determine the urban parameters which have significant effects on the air surface temperature distribution. The ManWhitney $U$ test was applied to identify the relationship between the land use type and the air temperature since the urban parameter is a nominal data type.

In this study, two urban parameters were extracted from the Landsat satellite image, namely green cover and built-up area. The radiometric calibration prior to data extraction from the Landsat satellite used image is essential. This calibration was performed to reduce the radiometric errors contained in the image. The carried out calibration includes the conversion of the digital number (DN) value into a surface reflectance value and sun angle correction. Two algorithms were used to perform the radiometric calibration procedures. Equation 1 shows the algorithm used to convert the DN value into surface reflectance value. The band-specific multiplicative rescaling factor quantized, and the calibrated standard product pixel value and band-specific additive rescaling factor were obtained from the metadata provided.

$$
\rho \lambda^{\prime}=M_{\rho} \times Q_{C A L}+A_{L}
$$

where $\rho \lambda^{\prime}$ - surface reflectance without sun angle correction

$M_{\rho}$ - band-specific multiplicative rescaling factor

$Q_{C A L}$ - quantized and calibrated standard product pixel value

$A_{\rho}$ - band-specific additive rescaling factor

Equation 2 shows the algorithm used to perform the sun angle correction on the converted surface reflectance value. The local sun elevation angle and the local solar zenith angle were obtained from the provided metadata.

$$
\rho \lambda=\frac{\rho \lambda^{\prime}}{\cos \left(\theta_{S Z}\right)}=\frac{\rho \lambda^{\prime}}{\sin \left(\theta_{S F}\right)}
$$

where $\Theta_{S Z}$ - Local sun elevation angle

$\Theta_{S E}$ - Local solar zenith angle 
The green cover data layer was extracted using the Normalized Different Vegetation Index (NDVI). This index is commonly used to extract the green vegetation from satellite images using a specific algorithm. This index is also suitable to be used within regions which have a green cover of over $30 \%$. Since the study area is rich of green vegetation (over $30 \%$ ), this index was suitable to be employed.

The Near Infrared (NIR)/Band 5 and Red/Band 4 bands of Landsat $8 \mathrm{OLI}$ images were used in order to generate the green cover data layers. These bands were used due to their properties that reflect and absorb specific spectrums within the sun radiation. Equation 3 shows the algorithm used to extract the NDVI values from the satellite images.

$$
N D V I=\frac{\text { Band } 5-B \text { and } 4}{B \text { and } 5+B \text { and } 4}
$$

Due to the arguments on the performance of the original NDBI, this study has employed a new algorithm to enhance the built-up data layer. The new algorithm involved three existing algorithms in order to eliminate the confusion in classifying the built-up areas. The involved algorithms are: the Normalized Difference Built-up Index (NDBI), the Normalized Difference Vegetation Index (NDVI), and the Modified Normalized Difference Water Index (MNDWI). As shown in Equation 4, the new algorithm was formed using the combination of the three existing algorithms.

$$
\text { BuiltUp Area }=N D B I-N D V I-M N D W I
$$

As suggested by Bhatti and Tripathi (2014), this study has performed the Principal Component Analysis (PCA) between Band 6 (Short-wave Infrared/SWIR1) and 7 (Short-wave Infrared/ SWIR2), as well as Band 10 (Thermal Infrared/TIRS1) and 11 (Thermal Infrared/TIRS2) in order to assign suitable pixel values. Equation 5 shows the algorithm used to extract the NDBI data layer. This algorithm employed 5 bands, namely Band 5, 6, 7, 10 and 11 in order to extract the built-up area. The NDVI layer was extracted using the same algorithm discussed in the previous subsection (referring to Equation 3). Shown in Equation 6 is the algorithm used to extract the MNDWI value. This algorithm used two different bands which are Band 3 and Band 7.

$$
\begin{gathered}
N D B I=\frac{(\text { PCA Band 6,7 }+ \text { PCA Band 10,11) }- \text { Band } 5}{(\text { PCA Band 6,7 }+ \text { PCA Band 10,11) + Band } 5} \\
M N D W I=\frac{\text { Band } 3-\text { Band } 7}{\text { Band } 3+\text { Band } 7}
\end{gathered}
$$

In this study, two types of urban parameter layers, namely terrain elevation and surface roughness, were derived from the LiDAR-based DEM data.

The Digital Terrrain Model (DTM) layer derived from the LiDAR dataset was used to generate the terrain elevation layer. Since the pixel size of the climate variables is $500 \mathrm{~m} \times 500 \mathrm{~m}$, the grid size for the terrain elevation layer should be resampled to also $500 \mathrm{~m} \times 500 \mathrm{~m}$. The mean terrain elevation was assigned as the new pixel value. The nearest neighbour resampling 
technique was used. This resampling technique was chosen to maintain the original pixel values after the calculation was made. The technique is also chosen to avoid excessive pixel smoothing which will alter the original DTM values. Equation 7 shows the formula used to calculate the mean terrain elevation.

$$
\text { Mean Terrain Elevation }=\frac{\sum \text { pixel values within } 500 \mathrm{~m} \times 500 \mathrm{~m}}{\sum \text { number of pixels within } 500 \mathrm{~m} \times 500 \mathrm{~m}}
$$

The Digital Surface Model (DSM) obtained from the LiDAR-based dataset was used to produce the surface roughness. Due to the limitation to produce the Frontal Areal Index (FAI), this study has employed the technique suggested by Grohmann et al. (2011) in order to replace the FAl layer. Grohmann et al. (2011) has suggested that the surface roughness can be represented by calculating the standard deviation of the slope. This method was employed in this study to derive the surface roughness layer. To derive the standard deviation of the slope or the surface roughness, three different equations were used. DSM values were first converted into slope (in radian) values using Equation 8. Equation 9 was used to convert the slope values into a degree unit.

The Digital Surface Model (DSM) obtained from the LiDAR-based dataset was used to produce the surface roughness. Due to the limitation to produce the Frontal Areal Index (FAI), this study has employed the technique suggested by Grohmann et al. (2011) in order to replace the FAl layer. Grohmann et al. (2011) has suggested that the surface roughness can be represented by calculating the standard deviation of the slope. This method was employed in this study to derive the surface roughness layer. To derive the standard deviation of the slope or the surface roughness, three different equations were used. DSM values were first converted into slope (in radian) values using Equation 8. Equation 9 was used to convert the slope values into a degree unit.

$$
\begin{aligned}
& \text { slope }(\text { in radian })=\tan ^{-1} \sqrt{\left(\frac{d z}{d x}\right)^{2}+\left(\frac{d z}{d y}\right)^{2}} \\
& \text { slope }(\text { in degree })=\tan ^{-1} \sqrt{\left(\frac{d z}{d x}\right)^{2}+\left(\frac{d z}{d y}\right)^{2}} \times 180 / \pi
\end{aligned}
$$

where

$$
\begin{aligned}
& \frac{d z}{d x}-\text { rate of change of the surface in horizontal } \\
& \frac{d z}{d y}-\text { rate of change of the surface in vertical }
\end{aligned}
$$

Then, the standard deviation of the slope was derived using Equation 10. The produced layer was later resampled into $500 \mathrm{~m} \times 500 \mathrm{~m}$ pixel resolution. 


$$
\sigma=\sqrt{\frac{1}{N} \sum_{i=1}^{N}\left(x_{i}-\mu\right)^{2}}
$$

where $\sigma$-standard deviation

$\mathrm{N}$ - number of samples

$\mathrm{x}$ - sample

$\mu-$ mean of samples

In this study, the building volume and the land use parameter layers were obtained and derived from the GIS-based vector datasets.

The estimation of the building volume within the city was made using Equation 11 . The building height information in building footprint data layer was used as the third dimension to estimate the building volume. The building volume is converted into percentage using the highest building (over $500 \mathrm{~m} \times 500 \mathrm{~m}$ area) as the highest volume. The building volume layer was converted into a raster data layer. The layer was then resampled into a $500 \mathrm{~m} \times 500 \mathrm{~m}$ pixel resolution.

$$
\text { Building Volume }(\%)=\frac{\left.\sum \text { (height } \times \text { footprint }\right)}{\left.\sum \text { (highest height } \times 500 \mathrm{~m} \times 500 \mathrm{~m}\right)} \times 100
$$

Land use type data layer was employed to represent the land use activities within the study area. In this study, the land use type data layer was obtained from the Department of Town and Regional Planning (JPBD) of Malaysia. The land use is classified into 18 classes. Table 4 shows the land use classes used by JPBD for the study area. Since this study was conducted using the $500 \mathrm{~m} \times 500 \mathrm{~m}$ resolution, this data layer was also resampled to match the other urban climate parameter data layers.

Land use types of the study area

Table 4

\begin{tabular}{|c|c||c|c|}
\hline No & Land use type & No & Land use type \\
\hline $\mathbf{1}$ & Residential & $\mathbf{1 1}$ & Religion Purposes \\
\hline $\mathbf{2}$ & Non-Developed Area & $\mathbf{1 2}$ & River and Drainage Reserved \\
\hline $\mathbf{3}$ & Business Area & $\mathbf{1 3}$ & Parking Space \\
\hline $\mathbf{4}$ & Utility & $\mathbf{1 4}$ & Cemetery \\
\hline $\mathbf{5}$ & Institution & $\mathbf{1 5}$ & Temporary Business Area \\
\hline $\mathbf{6}$ & Electric Reserved & $\mathbf{1 6}$ & Education \\
\hline $\mathbf{7}$ & Open Space and Recreation & $\mathbf{1 7}$ & Forest Reserved \\
\hline $\mathbf{8}$ & Industry & $\mathbf{1 8}$ & Roads \\
\hline $\mathbf{9}$ & Rail Reserved & & \\
\hline $\mathbf{1 0}$ & Terminal Station & &
\end{tabular}

The present study employed the WRF-ARW simulation to reproduce the air surface temperature for the specific date chosen. The simulation was spun up for two days (48 hours) to reconstruct the original weather on the selected dates $\left(24^{\text {th }}\right.$ March 2017$)$. The date is selected to coincide with the Landsat satellite image used in this study. The lateral boundary condition was fed every six hours by utilizing the NCEP FNL Operational Global Tropospheric Analysis data. The data was supplied by the Global Data Assimilation System (GDAS) with a 
resolution of $0.25^{\circ} \times 0.25^{\circ}$

The chosen physics schemes were a set of well-tried options conducted by Isa et al. (2018b). This option has successfully simulated the diurnal air surface temperature and the wind components of Kuala Lumpur City with an accuracy of over $90 \%$ in agreement with the ground observations. Using the same physics schemes as the previous study by Isa et al. (2018b), this study has simulated the diurnal air surface temperature and the wind components of the study area. Table 5 shows the physics schemes employed during the study.

\section{Employed physics schemes}

Table 5

\begin{tabular}{|l|l|}
\hline \multicolumn{1}{|c|}{ Physics Option } & \multicolumn{1}{c|}{ Scheme } \\
\hline Microphysics & WRF Single-Moment 6-class scheme \\
\hline Longwave Radiation & RRTM scheme \\
\hline Shortwave Radiation & Dudhia scheme \\
\hline Surface Layer & MM5 similarity \\
\hline Land Surface & Noah Land Surface Model \\
\hline Planetary Boundary Layer & Yonsei University scheme \\
\hline Cumulus Parameterization & Kain-Fritsch scheme \\
\hline
\end{tabular}

In the study, the diurnal air surface temperature and wind components were simulated using four nested domains with the grid size of $37.5 \mathrm{~km}(40 \times 40), 12.5 \mathrm{~km}(88 \times 88), 2.5 \mathrm{~km}(201 \times$ $201)$ and $0.5 \mathrm{~km}(151 \times 151)$. The dimensions in the parentheses are the grid dimensions designed in the easting and northing direction. Based on Fig. 4, the centre of all four domains were focused on the location of Kuala Lumpur City to provide a relaxation zone to the domains, intended to reduce the errors by employing the LBC (NCAR 2016). The largest domain (D01) covered a part of Southeast Asia region and the smallest domain (D04) was designed to focus on the Klang Valley region where the Kuala Lumpur City is located.

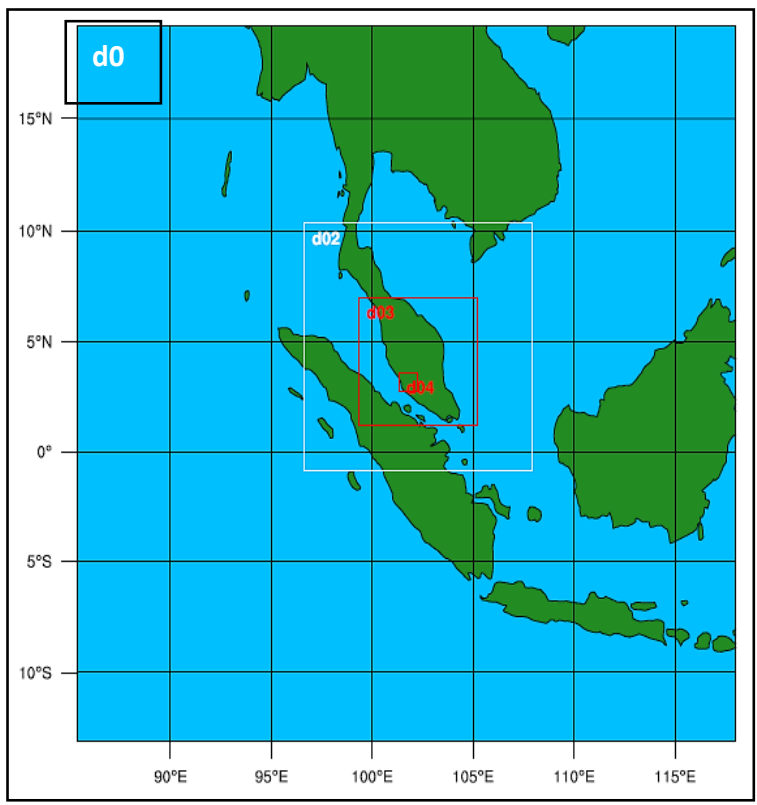

Fig. 4 - Designed simulation domains 
The four domains designed for the simulation are shown in Fig. 4. The parent domain covers several countries such as Malaysia, Thailand, Myanmar, Indonesia, Singapore and Brunei. The second and third domains were focused on the Peninsular of Malaysia with a different area coverage, as well as pixel sizes. The smallest domain was designed to cover the entire Kuala Lumpur City with the pixel size of $500 \mathrm{~m} \times 500 \mathrm{~m}$ in order to coincide with other prepared datasets.

The air surface temperature produced by WRF-ARW was stored in NetCDF data format. This format was converted into a GIS-based raster data layer to ease the data processing and analysis. Using the "Create NetCDF raster layer" tool developed in the ArcGIS software, hourly air surface temperature data layers were extracted. These layers were stored as a single raster layer for each hour.

The simulated hourly air surface temperature layers were then combined to produce the mean air surface temperature layer. The "Raster Calculator" tool was used to calculate the average of the air surface temperature layers. Since the simulated air surface temperature layers covered a large area, the masking technique was used to select the air surface temperature within the study area only.

\section{Results}

\section{Air Surface Temperature Distribution}

The distribution of the daily mean air surface temperature of Kuala Lumpur city simulated using the WRF-ARW simulation is shown in Fig. 5. Based on the result, it was found that the highest air surface temperature was of $30.3^{\circ} \mathrm{C}$ whereas the lowest air surface temperature was of 25.8 ${ }^{\circ} \mathrm{C}$. The highest air surface temperature was found in the south-western part of the city, near Sri Petaling, whereas the lowest air surface temperature was found in the north-eastern part, around Bukit Tabur.

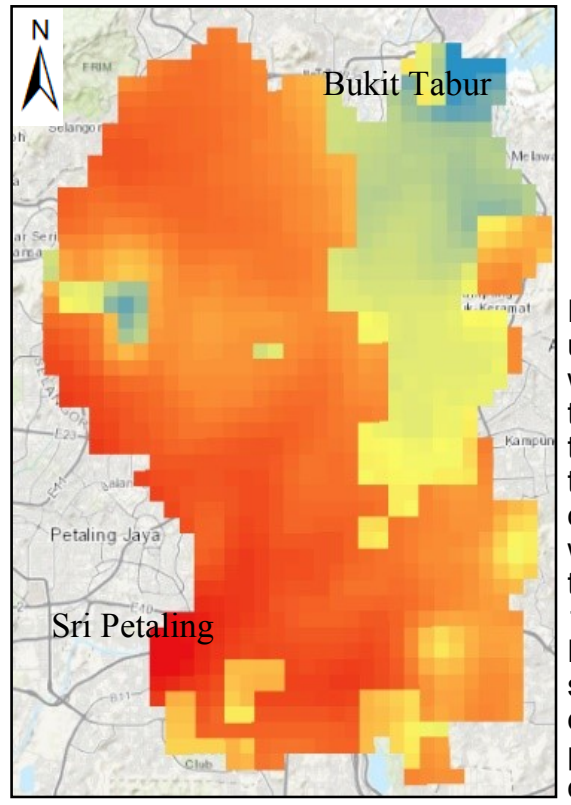

\section{Fig. 5- The distribution of air surface tempera- ture in Kuala Lumpur city}

Daily Mean Air Surface Temperature

High : $30.3^{\circ} \mathrm{C}$

Low : $25.8^{\circ} \mathrm{C}$

Hourly air surface temperature layers were produced using the WRF-ARW simulation model. The layers were validated against the ground observations from the Malaysia Meteorological Department (MMD) prior to further analysis. A very good agreement between the simulated air surface temperature and the observed air surface temperature were determined with over $90 \%$ agreements for each station. Based on this study, the RMSE of the model in 2014 were $1.0^{\circ} \mathrm{C}$, $1.1^{\circ} \mathrm{C}$ and $1.8^{\circ} \mathrm{C}$ for the Universiti Malaya, Subang and Pusat Pertanian Serdang stations respectively. Fig. 6 shows the agreements on linear relationships and the diurnal patterns of the air surface temperature produced by WRF-ARW and captured from the ground observations in three different stations. 


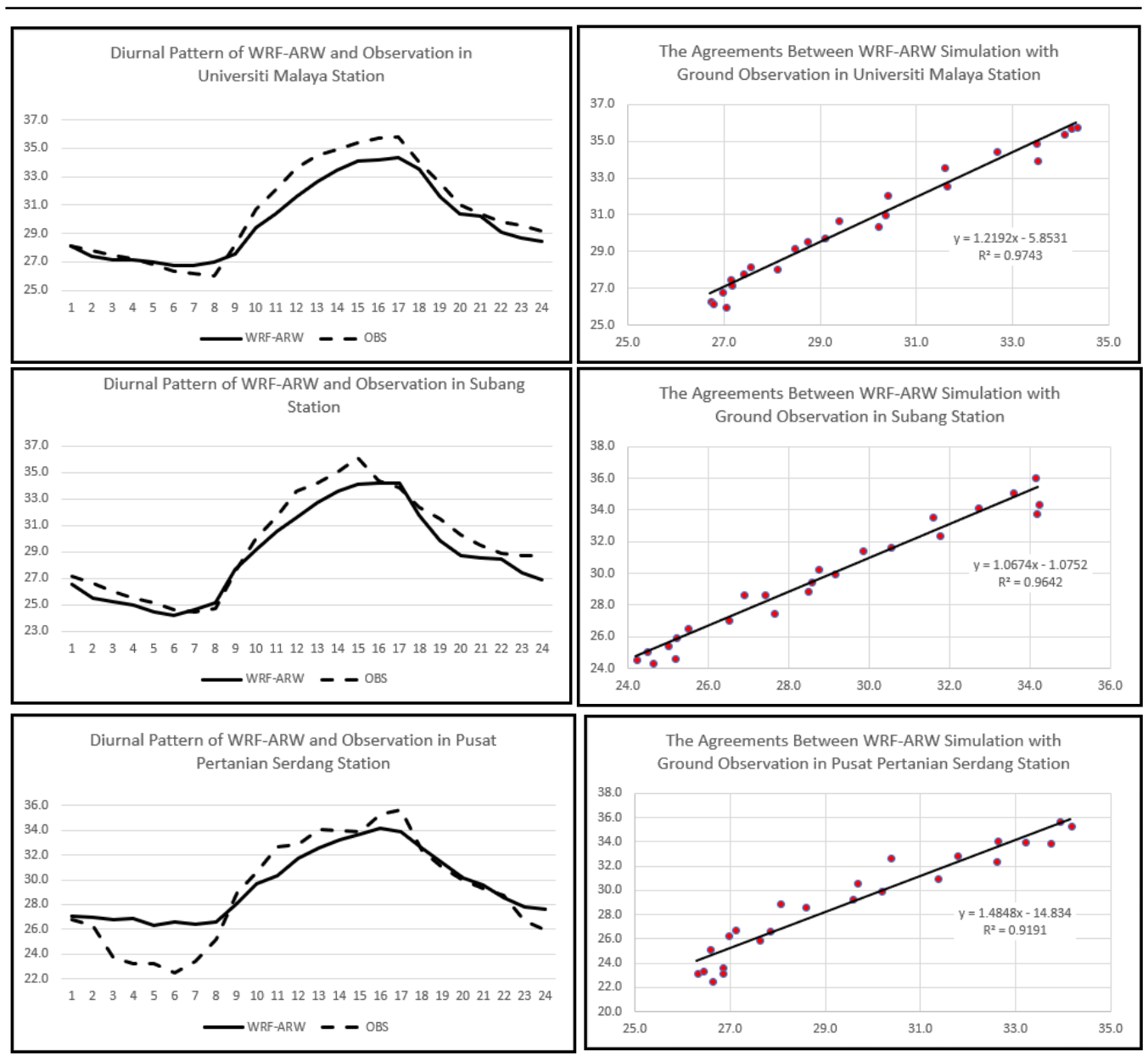

Fig. 6- The agreements and diurnal patterns of WRF-ARW simulation and ground observations in three different stations

\section{Urban Parameter Distribution}

Fig. 7 shows the spatial distribution of the urban parameters extracted and derived using remotely-sensed and GIS-based datasets. Fig. 7 (a) shows the distribution of the green cover existed within the city. From the result, it was identified that the distribution of the dense green cover was very small as compared to the non-green cover and mixed areas with the percentage of approximately $12 \%$. Most of the city was covered with the mixed built-up and green cover with approximately $83 \%$. The distribution of the built-up areas is shown in Fig. 7 (b). Based on the result, the Kuala Lumpur city was dominated, with more than half, by built-up areas. However, the urban areas are fragmented by the non-built-up areas which consist of the green covers and water bodies. Fig. 7 (c) shows the terrain profile of the Kuala Lumpur city. The highest point was found in Bukit Tabur, whereas the lowest point was found in Sri Petaling. The city was divided by Klang River which flows from the mountainous region towards the lower region in Sri Petaling and Puchong which created a valley-like region across the city. Surface roughness is portrayed in Fig. 7 (d). From the figure, it can be said that most of the 
Nurul Amirah ISA, Wan Mohd Naim WAN MOHD, Siti Aekbal SALLEH, Maggie Chel GEE OOI, Andy CHAN
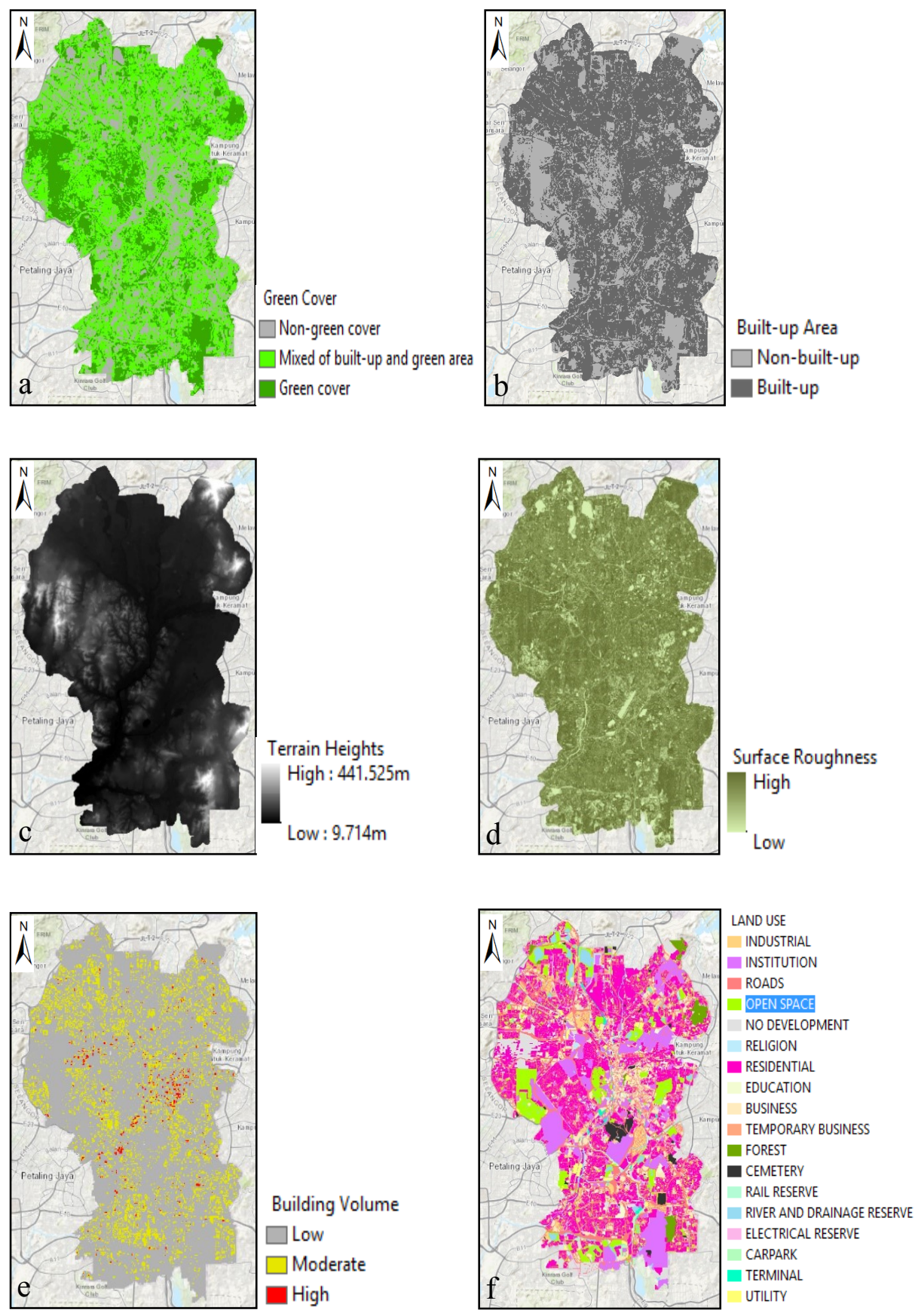

Fig. 7 - The urban parameter layers produced are:

(a) the green cover, (b) the built-up areas, (c) the terrain heights,

(d) the surface roughness, and (e) the building volume 
Kuala Lumpur city surface was rough with only some places were indicated as flat, such as the lakes in Jinjang and the Subang Airport. However, there are no extreme changes of the surface roughness within the entire city. The building volume distribution is shown in Fig. 7 (e). The present study found that the Kuala Lumpur city is not packed with high volume buildings. This may be due to the sparse distribution of the buildings within the city leading to the reduction of building volume on certain regions. Land uses are shown in Fig. 7 (f). There are sixteen different land use classes found in the entire study area. This may be due to the previous development plans which concentrated to develop the city by separating different uses in different locations.

\section{Urban Parameters' Correlation with the Thermal Environment}

Based on the Spearman Rho's test, it was found that all six urban parameters tested correlated the air surface temperature variation of the Kuala Lumpur city. From the results shown in Table 6 , it was found that the strongest correlation was indicated from the built-up areas with the $\mathrm{R}^{2}$ of 0.701 , whereas the weakest correlation was identified from the surface roughness with the $\mathrm{R}^{2}$ of 0.178 . The results also indicated that there were three urban parameters that contribute to the urban heating depicted by the positive $(+)$ correlation whereas two of them contribute to the urban cooling indicated by the negative (-) correlation. Based on the Man Whitney test, the result revealed that the land use type is correlated to the air surface temperature distribution of Kuala Lumpur city. This is indicated by the significant difference values $(p<0.05)$ calculated between each land use type.

The correlation between urban parameters and thermal variation

Table 6

\begin{tabular}{|c|c|c|c|}
\hline $\begin{array}{c}\text { Urban } \\
\text { Parameter }\end{array}$ & $\begin{array}{c}\text { Tested } \\
\text { value }\end{array}$ & $\begin{array}{c}\text { Type of } \\
\text { Correlation }\end{array}$ & Concluding Remarks \\
\hline Green cover & $\mathrm{R}^{2}=0.620$ & Negative & $\begin{array}{c}\text { High correlation - contributes to } \\
\text { urban cooling }\end{array}$ \\
\hline Built-up area & $\mathrm{R}^{2}=0.701$ & Positive & $\begin{array}{c}\text { High correlation - contributes to } \\
\text { urban heating }\end{array}$ \\
\hline Terrain heights & $\mathrm{R}^{2}=0.227$ & Negative & $\begin{array}{c}\text { Moderate correlation - } \\
\text { contributes to urban cooling }\end{array}$ \\
\hline Surface roughness & $\mathrm{R}^{2}=0.178$ & Negative & $\begin{array}{c}\text { Low correlation - contributes } \\
\text { to urban heating }\end{array}$ \\
\hline Building volume & $\mathrm{R}^{2}=0.358$ & Positive & $\begin{array}{c}\text { Moderate correlation }- \\
\text { contributes to urban heating }\end{array}$ \\
\hline Land Use & $<0.05$ & - & $\begin{array}{c}\text { Correlates with the } \\
\text { air surface temperature }\end{array}$ \\
\hline
\end{tabular}

Significant Urban Parameters Affecting the Thermal Environment

In the previous section, the six urban parameters tested were correlated and associated with the climate variables used to represent the urban climate condition. Therefore, a further test to examine their significance towards the variation of the urban climate condition were conducted. Based on the conducted test, it was found that five from the six urban parameters were significantly affecting the air surface temperature variation. The urban parameters are: built-up area, green cover, terrain heights, building volume and surface roughness, leaving the land use type as the only urban parameter which is not significantly affecting the air surface temperature distribution within the city.

The decision made is based on the significant difference found in the urban parameters 
distribution as denoted by the $p$-value of each urban parameter. Since the test cutoff value is 0.05 to show there is a significant difference within the sample, the p-value of less than 0.05 indicates that the urban parameters tested were significant in describing the urban climate condition of the study area. Table 7 shows the $p$ value obtained from the test for each urban parameter analysed in this study. The most significant urban parameter was the built-up area, whereas the least significant urban parameter was the building volume with the $p$-value $<0.05$. Therefore, it can be concluded that the thermal loads aspect of Kuala Lumpur city was affected by the five significant urban parameters, either the effect is positive or negative.

Table 7

The p-value of each urban parameter tested using the Kruskal-Wallis $\mathrm{H}$ test*

\begin{tabular}{|c|l|l|l|l|}
\hline Dependent & \multicolumn{1}{|c|}{ Variable } & p-value & \multicolumn{1}{|c|}{$\begin{array}{c}\text { Actual } \\
\text { p-value }\end{array}$} & $\begin{array}{c}\text { Level of signifi- } \\
\text { cance }\end{array}$ \\
\hline \multirow{4}{*}{$\begin{array}{c}\text { Air Surface } \\
\text { Temperature }\end{array}$} & Built-up areas & 0.000 & $2.955 \times 10-37$ & Significant \\
\cline { 2 - 5 } & Green cover & 0.000 & $3.367 \times 10-53$ & Significant \\
\cline { 2 - 5 } & Terrain elevation & 0.000 & $4.853 \times 10-13$ & Significant \\
\cline { 2 - 5 } & Building volume & 0.000 & $3.000 \times 10-6$ & Significant \\
\cline { 2 - 5 } & Land Use Type & 0.185 & $4.340 \times 10-23$ & Not Significant \\
\hline
\end{tabular}

${ }^{*}$ The null hypothesis was rejected, which indicated there was a significant difference within the urban parameters

\section{Discussion}

The correlation test revealed that the green cover within the Kuala Lumpur city contribute to the decrease in the air surface temperature. With the $\mathrm{R}^{2}$ of -0.620 , the correlation between the green cover and the air surface temperature was quite strong. Similarly, the previous studies in tropical climate cities also found that the existence of green cover is able to regulate and reduce the rising of the air surface temperature within urbanized areas (Buyadi et al. 2015, Isa et al. 2018b). This is because the green cover indicates the existence of chlorophyll which increases the rate of transpiration within plants which release oxygen as their waste product. As a result, the oxygen content within the environment increased which promotes new fresh air that maintains the air surface temperature at a low level (Isa et al. 2018b). Hence, the manipulation of the amounts of green cover to maintain the urban climate condition is a priority as been suggested by previous studies (Yusof 2013, Kanniah 2017).

Previously, many studies have documented that rapid urbanization leads to the fast conversion of green covers such as natural forests and croplands, which is the prime cause to the rise in the surrounding temperature that leads to the formation of UHI (Li 2018, Zhou et al. 2019). Due to urbanization, the green cover and croplands are replaced and fragmented with built-up areas (Salvati 2014) that increase the heat capacity storage which release more heat into the air, making the surrounding temperature to be hotter. Furthermore, the properties of the urban materials and the sky view factor obstructions lead to a slow rate of heat release within the city (Mohajerani et al. 2017). The present study also discovered similar phenomena occurring in the Kuala Lumpur city as documented by previous studies (Kanniah 2017, Ooi et al. 2017) with the $\mathrm{R}^{2}$ of 0.701 . The results of the present study are also in line with the results of the previous study which stated that the region with high built-up areas, such as $\mathrm{Kg} \mathrm{Baru,} \mathrm{experienced} \mathrm{high}$ temperatures as compared to the area with less built-up areas (Isa et al. 2017). The urban parameter's effect was also tested to be significant as indicated by the p-value of less than 0.05 . 
The present study discovered that the terrain heights affect the air surface temperature variation within the Kuala Lumpur city with a moderate correlation $\left(R^{2}=0.227\right)$ which coincided with the previous studies' findings. Since the correlation is negative, this showed that the higher the region, the lower the air surface temperature. The terrain height was also found to significantly affect the thermal distribution of the Kuala Lumpur city since the p-value of Kruskal -Wallis test is smaller than 0.05 . In general, the temperature in the troposphere is dropping by $1^{\circ} \mathrm{C}$ with every $150 \mathrm{~m}$ increase in altitude, making the high lands to be colder than the lower lands (Amos 2017). In higher regions, the human activities which release the anthropogenic heat occur less, making this region to be cooler than the downhill (Doan and Kusaka 2015). Even though the mountainous regions tend to slow down the wind speed, the top hill regions experience high wind blows since there are no obstructions found. Furthermore, the distribution of rainfalls and precipitations is higher in higher regions which leads to the reduction of the air surface temperature (Kattel and Yao 2018).

Another tested urban parameter which significantly affects the variation of the air surface temperature was the building volume. The conducted correlation test showed that the building volume correlated with the variation of the air surface temperature with a moderate correlation $\left(R^{2}=0.358\right)$. In the previous study by $\mathrm{Ng}$ et al. $(2011)$, the building volume is blamed to have the most significant impact towards the air surface temperature within the tropical environment. However, this study revealed that the effect of the building volume on the air temperature variation within the city is less significant. This might be due to the less compact areas in the Kuala Lumpur city as compared to Hong Kong. High volume buildings in Kuala Lumpur city are usually fragmented with green covers (Isa et al. 2017), making the urban parameter to be less dominant than the others based on the $\mathrm{p}$-value obtained from the Kruskal-Wallis $\mathrm{H}$ test. However, the building volume was still listed as one of the significant urban parameters that can explain the variations of the air surface temperature within the Kuala Lumpur city.

In the study, the surface roughness was tested to be correlated with the variation of the air surface temperature in the Kuala Lumpur city with the $R^{2}$ of 0.178 . However, this correlation was quite weak. Even though previous studies suggested that the surface roughness should be considered to enhance the air ventilation and wind blows within the city (Ren et al. 2011, Ng et al. 2012), this study identified that the urban parameter was less significant, affecting the variation of the air surface temperature of the Kuala Lumpur city since the $p$-value closes to 0.05 . The contrast in the result might be due to the less compact urban areas in the previous studies. As mentioned before, the Kuala Lumpur city does have tall buildings with high building volumes which increase the building density of an area, but still, the roughness of the city's surface is not comparable to the other high-density cities such as Hong Kong and Taiwan. Moreover, it was found that Kuala Lumpur was developed on a flat plain with no extreme changes of terrain. Other than that, the higher roughness values are also associated with green covers which obstruct the wind blows, but at the same time, they have positive effects towards the thermal variation.

The last parameter tested in this study is represented by the land uses. The land use is classified based on the Malaysian local urban planning classes. Even though this parameter was tested to correlate with the variation of the air surface temperature, the further test revealed that this parameter does not significantly affect the variation of the thermal environment within the city. The little contrast found in this study may be due to the different populations within the city as compared to the previous study areas studied by Raghavan et al. (2015) and Morini et al. (2016). The human activities might also be different between these cities, and it therefore leads to less energy consumptions as compared to other cities. 


\section{Conclusions}

In the tropical city of Kuala Lumpur, the green cover, built-up areas, terrain heights and the building volume strongly influenced the air surface temperature variation. As expected, the built -up area and the building volume contribute to the urban heating phenomenon, whereas the green cover and the terrain heights contribute to the urban cooling phenomenon. From this study, even though all six urban parameters correlated with the air surface temperature variation within the Kuala Lumpur city, only five of them significantly had an effect on the thermal condition of the city. Hence, the present study suggests that the variation of the thermal environment of the Kuala Lumpur city can be best explained by five urban parameters which are: the green cover, the built-up areas, the terrain heights, the building volume and the surface roughness. The divergence effects of all studied urban parameters enlightened the complex interactions of the urban physical characteristics on the urban climate of Kuala Lumpur city.

The present study has provided important evidences concerning the effects of the urban physical characteristics on the thermal variation of a tropical city like Kuala Lumpur. This discovery is valuable for examining the implications of the urban physical characteristics for urban climate sustainability to enhance the quality of the urban natural environment. As such, the findings of this study can be integrated with other climate-related aspects, namely the urban fabric and materials, the urban structure, the artificial heat production, evapotranspiration, pollution, and human activities, in order to emphasize the urban climate system complexity in tropical cities for a comprehensive understanding. Hence, the efforts of integrating the urban climatic information during the urban planning decision making can be accomplished. Such efforts have long been practised by the developed countries, but, the recent studies on implementing the climate-related aspects in urban planning have shown that decision making is increasingly undertaken in the developing countries. There is a potential of translating the urban climate condition into a simpler "language" using maps to inform urban planners and policy makers of the urban climate behaviour so that such information can be seriously considered during any development planning, and this will be our future research focus.

\section{Acknowledgements}

The authors would like to express their gratitude to the Universiti Teknologi MARA (UiTM) for funding this project under Geran Bestari Perdana 600-IRMI/DANA 5/3 BESTARI (P) (074/2018).

\section{References}

ACERO J. A., KUPSKI S., ARRIZABALAGA J., KATZSCHNER L. (2015), Urban climate multi-scale modelling in Bilbao (Spain): A review, Procedia Engineering 115, 3-11.

ALOBAYDI D., BAKARMAN M. A., OBEIDAT B. (2016), The impact of urban form configuration on the urban heat island: The case study of Baghdad, Iraq, Procedia Engineering $145,820-827$.

AMENGUAL A., ROMERO R., HOMAR V., RAMIS C., ALONSO S. (2007), Impact of the lateral boundary conditions resolution on dynamical downscaling of precipitation in Mediterranean Spain, Climate Dynamics 29, 487-499.

AMOS J. (2017), Our Earth, Parragon, Bath.

ARIFWIDODO S. D., TANAKA T. (2015), The characteristics of urban heat island in Bangkok, Thailand, Procedia - Social and Behavioral Sciences 195, 423-428.

BHATTI S. S., TRIPATHI N. K. (2014), Built-up area extraction using Landsat $8 \mathrm{OLI}$ imagery, GIScience \& Remote Sensing 51 (4), 445-467.

BUYADI S. N. A., WAN MOHD W. M. N., MISNI A. (2013), Impact of land use changes on the surface temperature distribution of area surrounding the National Botanic Garden, Shah 
Alam, Procedia - Social and Behavioral Sciences 101, 516-525.

BUYADI S. N. A., WAN MOHD W. M. N., MISNI A. (2015), Vegetation's role on modifying microclimate of urban resident, Procedia - Social and Behavioral Sciences 202, 400407.

DAVIES T. (2014), Lateral boundary conditions for limited area models, Quarterly Journal of the Royal Meteorological Society 140 (678), 185-196.

DENIS B., LAPRISE R., CAYA D. (2003), Sensitivity of a regional climate model to the resolution of the lateral boundary conditions, Climate Dynamics 20, 107-126.

DOAN Q.-V., KUSAKA H. (2015), Numerical study on regional climate change due to the rapid urbanization of greater Ho Chi Minh City's metropolitan area over the past 20 years, International Journal of Climatology 36 (10), 3633-3650.

ELSAYED I. S. M. (2012), A study on the urban heat island of the city of Kuala Lumpur, Malaysia, Journal of King Abdulaziz University: Met., Env. \& Arid Land Agric. Sci., 23 (2), 121 134.

GIRIDHARAN R. (2016), Urban climate modeling: challenges in tropics, in: Emmanuel R. (ed.), Urban climate challenges in the tropics: Rethinking Planning and Design Opportunities, Imperial College Press, London, pp. 255-304.

GRIMMOND C. S. B., ROTH M., OKE T. R., AU Y. C., BEST M., BETTS R., CARMICHAEL G., CLEUGH H., DABBERDT W., EMMANUEL R., FREITAS E., FORTUNIAK K., HANNA S., KLEIN P., KALKSTEIN L. S., LIU C. H., NICKSON A., PEARLMUTTER D., SAILOR D., VOOGT J. (2010), Climate and more sustainable cities: Climate information for improved planning and management of cities (Producers/Capabilities Perspective), Procedia Environmental Sciences 1, 247-274.

GROHMANN C. H., SMITH M. J., RICCOMINI C. (2011), Multiscale analysis of topographic surface roughness in the Midland Valley, Scotland, IEEE Transactions on Geoscience and Remote Sensing 49 (4), 1200-1213.

HWANG Y.-T., XIE S.-P., DESER C., KANG S. M. (2017), Connecting tropical climate change with Southern Ocean heat uptake, Geophysical Research Letters 44 (18), 9449-9457.

IBRAHIM I., SAMAH A. A. (2011), Preliminary study of urban heat island: Measurement of ambient temperature and relative humidity in relation to landcover in Kuala Lumpur, 19th International Conference on Geoinformatics, 1-5.

IBRAHIM I., SAMAH A. A., FAUZI R. (2014), The review for the use of urban climatic map in the land use plan for urban planning, Planning Malaysia: Urban Planning and Local Governance 3, 95-110.

ISA N. A., SALLEH S. A., WAN MOHD W. M. N., CHAN A. (2018a), Kuala Lumpur city of tomorrow: Integration of geospatial urban climatic information in city planning, Theoretical and Empirical Researches in Urban Management 13 (4), 5-27.

ISA N. A., WAN MOHD W. M. N., SALLEH S. A. (2017), The effects of built-up and green areas on the land surface temperature of the Kuala Lumpur City, The International Archives of the Photogrammetry, Remote Sensing and Spatial Information Sciences 42, 107112.

ISA N. A., WAN MOHD W. M. N., SALLEH S. A., OOI M. C. G. (2018b), The effects of green areas on air surface temperature of the Kuala Lumpur city using WRF-ARW modelling and Remote Sensing technique, IOP Conference Series: Earth and Environmental Science 117,012012

JAMEI E., JAMEI Y., RAJAGOPALAN P., OSSEN D. R., ROUSHENAS S. (2015), Effect of built-up ratio on the variation of air temperature in a heritage city, Sustainable Cities and Society 14, 280-292.

KANNIAH K. D. (2017), Quantifying green cover change for sustainable urban planning: A case of Kuala Lumpur, Malaysia, Urban Forestry \& Urban Greening 27, 287-304.

KATTEL D. B., YAO T. (2018), Temperature-topographic elevation relationship for high mountain terrain: an example from the southeastern Tibetan Plateau, International Journal of Climatology 38 (S1), e901-e920. 
LI S. (2018), Change detection: how has urban expansion in Buenos Aires metropolitan region affected croplands, International Journal of Digital Earth 11 (2), 195-211.

MOHAJERANI A., BAKARIC J., JEFFREY-BAILEY T. (2017), The urban heat island effect, its causes, and mitigation, with reference to the thermal properties of asphalt concrete, Journal of Environmental Management 197, 522-538.

MORINI E., TOUCHAEI A. G., CASTELLANI B., ROSSI F., COTANA F. (2016), The impact of albedo increase to mitigate the urban heat island in Terni (Italy) using the WRF model, Sustainability 8 (10), 999.

NATIONAL CENTER FOR ATMOSPHERIC RESEARCH (2016), Weather Research and Forecasting Model: User's guides for the Advanced Research WRF (ARW) modeling system, version 3, NCAR, Retrieved from: www.mmm.ucar.edu.

NG E., REN C., KATZSCHNER L. (2012), Urban Climatic Mapping in Hong Kong, Journal of Heat Island Institute International 7 (2), 55-64.

NG E., YUAN C., CHEN L., REN C., FUNG J. C. H. (2011), Improving the wind environment in high-density cities by understanding urban morphology and surface roughness: A study in Hong Kong, Landscape and Urban Planning 101 (1), 59-74.

OOI M. C. G., CHAN A., SUBRAMANIAM K., MORRIS K. I., OOZEER M. Y. (2017), Interaction of Urban Heating and Local Winds During the Calm Intermonsoon Seasons in the Tropics, JGR Atmospheres 122 (21), 499-523.

RAGHAVAN K., MANDLA V. R., FRANCO S. (2015), Influence of urban areas on environment: Special reference to building materials and temperature anomalies using geospatial technology, Sustainable Cities and Society 19, 349-358.

RAMAKRESHNAN L., AGHAMOHAMMADI N., FONG C. S., GHAFFARIANHOSEINI A., GHAFFARIANHOSEINI A., WONG L. P., HASSAN N., SULAIMAN N. M. (2018), A critical review of Urban Heat Island phenomenon in the context of Greater Kuala Lumpur, Malaysia, Sustainable Cities and Society 39, 99-113.

REN C., NG E. Y.-Y., KATZSCHNER L. (2011), Urban climatic map studies: a review, International Journal of Climatology 31 (15), 2213-2233.

SALLEH S. A., LATIF Z. A., WAN MOHD W. M. N., CHAN A. (2013), Factors Contributing to the Formation of an Urban Heat Island in Putrajaya, Malaysia, Procedia - Social and Behavioral Sciences 105, 840-850.

SALVATI L. (2014), Urban growth and the spatial structure of a changing region: An integrated assessment, Journal of Urban and Regional Analysis 6 (1), 5-14.

SHAHARUDDIN A., NOORAZUAN M. H., TAKEUCHI W., NORAZIAH A. (2014), The effects of Urban Heat Islands on Human Comfort: A Case of Klang Valley Malaysia, Global Journal on Advances in Pure \& Applied Sciences 2, 1-8.

TANGANG T. M. F., LIEW J. N., SALIMUN E., SEI K. M., LE L. J., MUHAMAD H. (2012), Climate change and variability over Malaysia: Gaps in science and research information, Sains Malaysiana 41 (11), 1355-1366.

WARD P. J., EISNER S., FLÖRKE M., DETTINGER M. D., KUMMU M. (2014), Annual flood sensitivities to El Niño-Southern Oscillation at the global scale, Hydrol. Earth Syst. Sci. 18, 47-66.

WONG C. L., LIEW J., YUSOP Z., ISMAIL T., VENNEKER R., UHLENBROOK S. (2016), Rainfall Characteristics and Regionalization in Peninsular Malaysia Based on a High Resolution Gridded Data Set, Water 8 (11), 500.

YUEN B., KONG L. (2009), Climate change and urban planning in Southeast Asia, Surveys and Perspectives Integrating Environment \& Society 2 (3), 1-20.

YUSOF M. J. M. (2013), True colours of urban green spaces: identifying and assessing the qualities of green spaces in Kuala Lumpur, Malaysia, University of Edinburg, Retrieved from: www.era.ed.ac.uk.

YUSUF Y. A., PRADHAN B., IDREES M. O. (2014), Spatio-temporal Assessment of Urban Heat Island Effects in Kuala Lumpur Metropolitan City Using Landsat Images, Journal of the Indian Society of Remote Sensing 42, 829-837. 
ZHOU D., XIAO J., BONAFONI S., BERGER C., DEILAMI K., ZHOU Y., FROLKING S. YAO R., QIAO Z., SOBRINO J. A. (2019), Satellite remote sensing of surface urban heat islands: Progress, challenges, and perspectives, Remote Sensing 11 (1), 48.

Initial submission: 03.05.2019

Revised submission: 24.10.2019

Final acceptance: 03.12.2019

Correspondence: Centre of Studies of Surveying Science and Geomatics, Faculty of Architecture, Planning and Surveying, Universiti Teknologi MARA, 40450 Shah Alam, Selangor Darul Ehsan, Malaysia.

Email: aekbal@uitm.edu.my 
